\title{
REACTOR BOLT EVALUATION TESTS
}

(EML-13)

\author{
Westinghouse Electric Corporation \\ Astronuclear Laboratory \\ P. O. Box 10864 \\ Pittsburgh, Pennsylvania 15236
}

PREPARED BY:

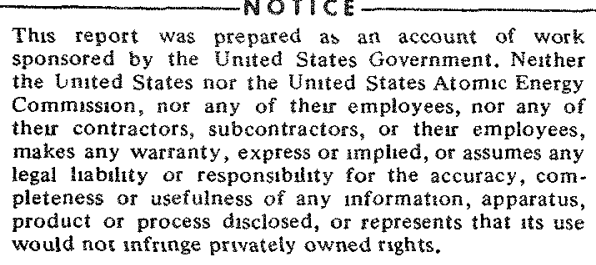

This report was prepared as an account of work by the United States Government. Nether Co unted States nor the Unted States Atomic Energy their contractors, subcontractors, or thear employees, makes any warranty, exptess or mplied, or assumes any

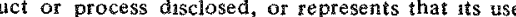

would nos infringe provately owned rights.

a MTreba

A. N. Krebs

Support Structure \& Cryogenic Experiments

\section{APPROVED BY:}

M. 1 . Bufano

N. . Bifand/Supervisor

Support Structure \& Cryogenic Experiments

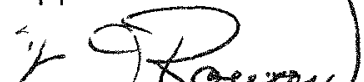

W. t. Bow an, Manager

Engineering Mechanics

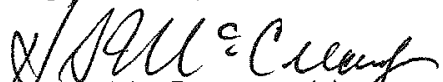

14. S. McCreary, Monager

Experimental Engingering

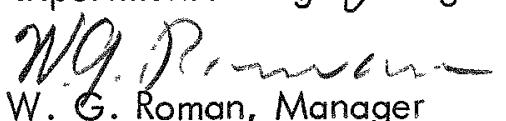

Reactor Engineering, NERVA Project

/fep
INFORMATION CATEGORY
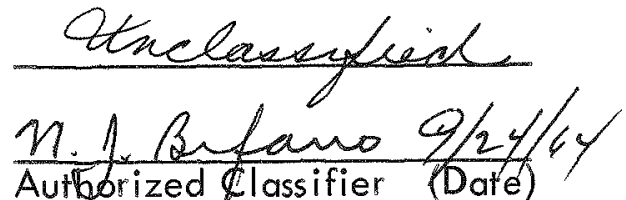


\section{DISCLAIMER}

This report was prepared as an account of work sponsored by an agency of the United States Government. Neither the United States Government nor any agency Thereof, nor any of their employees, makes any warranty, express or implied, or assumes any legal liability or responsibility for the accuracy, completeness, or usefulness of any information, apparatus, product, or process disclosed, or represents that its use would not infringe privately owned rights. Reference herein to any specific commercial product, process, or service by trade name, trademark, manufacturer, or otherwise does not necessarily constitute or imply its endorsement, recommendation, or favoring by the United States Government or any agency thereof. The views and opinions of authors expressed herein do not necessarily state or reflect those of the United States Government or any agency thereof. 


\section{DISCLAIMER}

Portions of this document may be illegible in electronic image products. Images are produced from the best available original document. 


\section{TABLE OF CONTENTS}

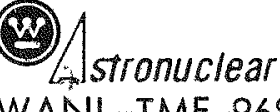

WANL-TME-968

\subsection{Summary}

2.0 Introduction

$\underline{\text { Page }}$

3.0 Purpose

4.0 General Test Description

5.0 Test Results

5.1 Torque Tests - Fuel Cluster Hardware

5.2 Tie Rod Holder Tension Failure Tests

5.3 Core Support Plate - Core Support Ring Bolts

5.4 Core Support Ring - Outer Reflector Tapped Bushing Attachment Bolts

5.5 Barrel Retaining Screw

5.6 Instrumentation Support Screw Galling Test (Lead Holder Attachment Screw)

5.7 Instrumentation Support Retainer Screw Galling Tests (Lead Fastening Screw)

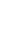

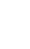

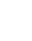

5

6.0 Conclusions 7

$\begin{array}{ll}\text { Figures } & 8\end{array}$ 


\section{LIST OF FIGURES}

Number

1

2

3

4

5

6
Title

Torque Vs Axial Preload (Cluster Nut - Tie Rod Holder Test)

Torque Vs Axial Preload (Core Support Plate Core Support Ring Attachment Bolts)

Torque Vs Axial Preload (Core Support Ring Outer Reflector Tapped Bushing Bolts)

Instrumented Tie Rod Holder, Fuel Cluster Nut and Locking Device

Tie Rod Holder Holes in Simulated Core Support Plate Block

Locking Device Slots in Simulated Core Support Plate Block

Instrumented 1/4-28 Bolt and Test Rig

Instrumented 5/16-24 Bolt, Ni-Span-C Barrel

Nut and Test Rig

Barrel Screw and Anchor Nut Plate Assembly

Test Specimens - Instrumentation Lead Retainer
Page

8

9

10

11

12

13

15

16

17 
1.0 SUMMARY

A test program was carried out to evaluate the assembly torque-preload characteristics of various threaded fasteners used in the NRX-A reactors. All of these evaluation tests were performed on specification grade reactor fasteners using test fixtures which provided close simulation of the service environments of these parts. No excessive friction or galling problems were experienced during assembly or disassembly, and the specified design requirements for axial preload and strength at the specified assembly torques were met.

Threaded fastener assemblies of different material combinations were tested at cryogenic conditions to determine whether differential thermal contractions would have an important effect on the disassembly torque. No measurable temperature effect was observed.

The individual rests are described in detail in Paragraph 5.0.

\section{$2.0 \quad$ INTRODUCTION}

Friction and galling tests of threaded fasteners currently used in the NRX-A reactor were performed. These tests were conducted in test rigs which simulated reactor conditions that could affect the results. The fasteners were tested with their locking devices in simulated reactor components which would accurately duplicate the fastener friction conditions during reactor assembly and disassembly. The resulting bolt preloads were measured to ascertain their ability to meet the design requirements. 


\subsection{PURPOSE}

The friction and galling characteristics of many of the special materials used for threaded fasteners in the reactor are either unknown or not readily available. Also, the geometry of many of the fasteners particularly of the locking devices, are of unusual design whith unknown friction effects.

These tests were performed to ascertain that the threaded fastener specification assembly torques would develop the desired design axial preloads but would not cause overstress conditions, and that excessive friction and galling would not occur as a result of fastener and metal combination incompatibilities.

\subsection{GENERAL TEST DESCRIPTION}

To obtain axial bolt loads, strain gages were mounted on the bolts in a manner responsive to axial bolt strains. In some cases, the gages were cemented to the external surfaces of the bolts, and in other cases holes were drilled axially through the bolts and the gages were cemented to the interior walls. Typical externally and internally instrumented bolts are shown in Figures 4 and 7, respectively. Standard electronic bridge resistance measuring equipment was used for strain measurements, and calibrated torque wrenches were used for torque measurements.

The torque versus axial load tests were performed at room temperature. Applied torques were limited to values which did not yield the threaded fasteners. Galling tests were performed by torquing the bolts to their specification tightening torques and then measuring the loosening (back-off) torques. After each torque test, the specimens were examined for signs of galling. 
To determine the effects of differential thermal contraction on galling, the fasteners were torqued to full design torques and then immersed in liquid nitrogen for a minimum period of 1 hour, after which they were refurned to room temperature and disassembled. The loosening (back-off) torques were measured and the fasteners were then examined for signs of galling.

\subsection{TEST RESULTS}

\subsection{Torque Tests - Fuel Cluster Hardware}

Tie rod holder part assemblies (see Figures 4, 5 and 6) consisting of reactor grade tie rod holders, cluster nuts and locking devices were assembled in a test block with and without "Neolube" lubricant to determine the relationship between tightening torques and tie rod holder axial loads.

The results of these tests are shown in Figure 1. Envelope No. 1 of this figure includes all the experimentally determined values of tie rod holder axial loads without lubricant on any of the parts. Envelope No. 2 (dotted lines) includes all values for "Neolube" lubricated tie rod holder threads only, and Envelope No. 3 includes all values for "Neolube" lubricated threads and all other bearing surfaces of the cluster nut. The beneficial effect of applying lubricant is obvious from these load envelopes which show that lubrication increases the minimum axial load over the unlubricated condition as much as $73 \%$ within the range of specified assembly torque $(325$ to $410 \mathrm{in} .-1 \mathrm{~b})$.

The maximum anticipated applied load on each tie rod holder during reactor operation is less than $500 \mathrm{lb}$ compared to the minimum experimentally determined tightening preload, without lubricant, of $1140 \mathrm{lb}$. 
Therefore, although the lubricant is beneficial, it was found unnecessary and the fasteners met their design preload requirements without lubricant.

5.2 Tie Rod Holder Tension Failure Tests

Some of the tie rod holders were lested for axial strength in the tensile test machine. The failing loads ranged from 7175 to $8550 \mathrm{lb}$, values far exceeding the axial load, $3200 \mathrm{lb}$, which resulted from the maximum prescribed assembly torque.

5.3 Core Support Plate - Core Support Ring Bolts

Torque versus axial preload tests of specification grade bolts were performed. Neolube lubricant was applied to the threads and all bearing surfaces in accordance with standard reactor assembly procedures before testing. The test fixture and an instrumented test bolt is shown in Figure 7. The significance of the test results is illustrated by the two curves of Figure 2. These curves envelope all of the axial loads which were measured during the torquing tests on the test specimens. The main area of interest lies between the minimum and maximum assembly torques of 80 and $90 \mathrm{in} .-\mathrm{lb}$, for which the preloads were 1000 and $1830 \mathrm{lb}$, respectively.

\subsection{Core Support Ring - Outer Reflector Tapped Bushing Attachment Bolts}

Torque versus axial load tests were performed on these bolts using complete sets of test specimen hardware, including a bolt, a locking device and a $\mathrm{Ni}$-Span-C alloy bushing with silver plated threads. The test specimens are shown in Figure 8.

The results of these tests substantiated the adequacy of the bolts in meeting their design requirements for preload. All of the measured preloads were within the envelope of the two curves shown in Figure 3. The preloads 
for the minimum (140 in. $-1 \mathrm{~b})$ and the maximum $(150 \mathrm{in.}-\mathrm{lb})$ specification assembly torques were 830 and $1480 \mathrm{lb}$, respectively.

\subsection{Barrel Retaining Screw Tests}

Galling tests were performed on specification grade barrel retaining screws which attach the inner reflector aluminum barrel to the core support ring. Each screw was assembled in a new locking anchor nut (without silver plating) for each test. A test plate, representing the tabs on the support ring, to which the anchor nuts are assembled, is shown in Figure 9. Torque measurements were made on each retaining screw to test the ir capability of turning in the locking anchor nut at the maximum specification assembly torque of $50 \mathrm{in.}-1 \mathrm{~b}$ and insure that the prescribed assembly torque would properly seat the shoulder of the screw against the plate without galling either the screw or anchor nut threads of causing any other damage to the hardware. Galling effects were determined by measuring the torque necessary to loosen (back-off) the screw after assembling it in the test plate at its specification assembly torque.

Tests were also conducted to determine the failure torques of the internal wrenching heads of the screw specimens.

All of the screws were easily assembled in the anchor nuts without exceeding their specification assembly torques, and seated solidly against the plate within the prescribed 45 to $50 \mathrm{in}$. $-1 \mathrm{~b}$, assembly torque value. "Back-off" torques were found to be less than the applied assembly torques, indicative of no galling, and no galling effects were apparent from visual examination of the threads after the tests. The failure torques of the internal wrenching heads of the screws ranged from 60 to $71 \mathrm{in.}-1 \mathrm{~b}$ and were considered satisfactory. 
5.6 Instrumentation Support Screw Galling Test (Lead Holder Attachment Screw) Galling tests were performed on the screws which attach the instrumentation lead retainers to the core support plate and the nozzle and dome end support rings. Specification grade hardware was tested; each set consisting of a lead retainer, a retainer attachment screw and a test block. Test specimens were tested in aluminum test blocks to represent installations on the core support plate, and in titanium test blocks to represent installations on the nozzle and dome end support rings. These parts are shown in Figure 10. Both room and cryogenic temperature effects on galling were investigated. To perform the tests the screws were torqued to their maximum specification assembly torque of $50 \mathrm{in}$ - $1 \mathrm{lb}$ and the "back-off" (loosening) torques were measured to test for any galling tendencies.

Cryogenic operational temperature effects were simulated by immersing fully torqued specimens in liquid nitrogen for a minimum period of one hour, after which they were retruned to room temperature. Upon temperature stabilization they were tested for galling by measuring the screw "back-off" torques.

Neither the "back-off" torques nor visual examinations revealed any galling.

5.7 Instrumentation Support Retainer Screw Galling Tests (Lead Fastening Screw) Tests were performed on the screws which are used to hold the instrumentation leads in the lead holder slots as shown in Figure 10. These screws were torqued to the specification assembly torque of $20 \mathrm{in}$ - $=1 \mathrm{~b}$ after which the "back-off" torques were measured to test for galling. No galling occurred in any of the specimens. 


\subsection{CONCLUSIONS}

No excessive friction or galling of the threaded fastener assemblies was experienced during assembly and disassembly, and the specified design requirements for axial preload and strength at the assembly forques were met. Cryogenic temperature tests of the instrumentation lead holder hardware indicated that the differential thermal contractions expected during reactor operation would not have any significant effect on the disassembly torque. 


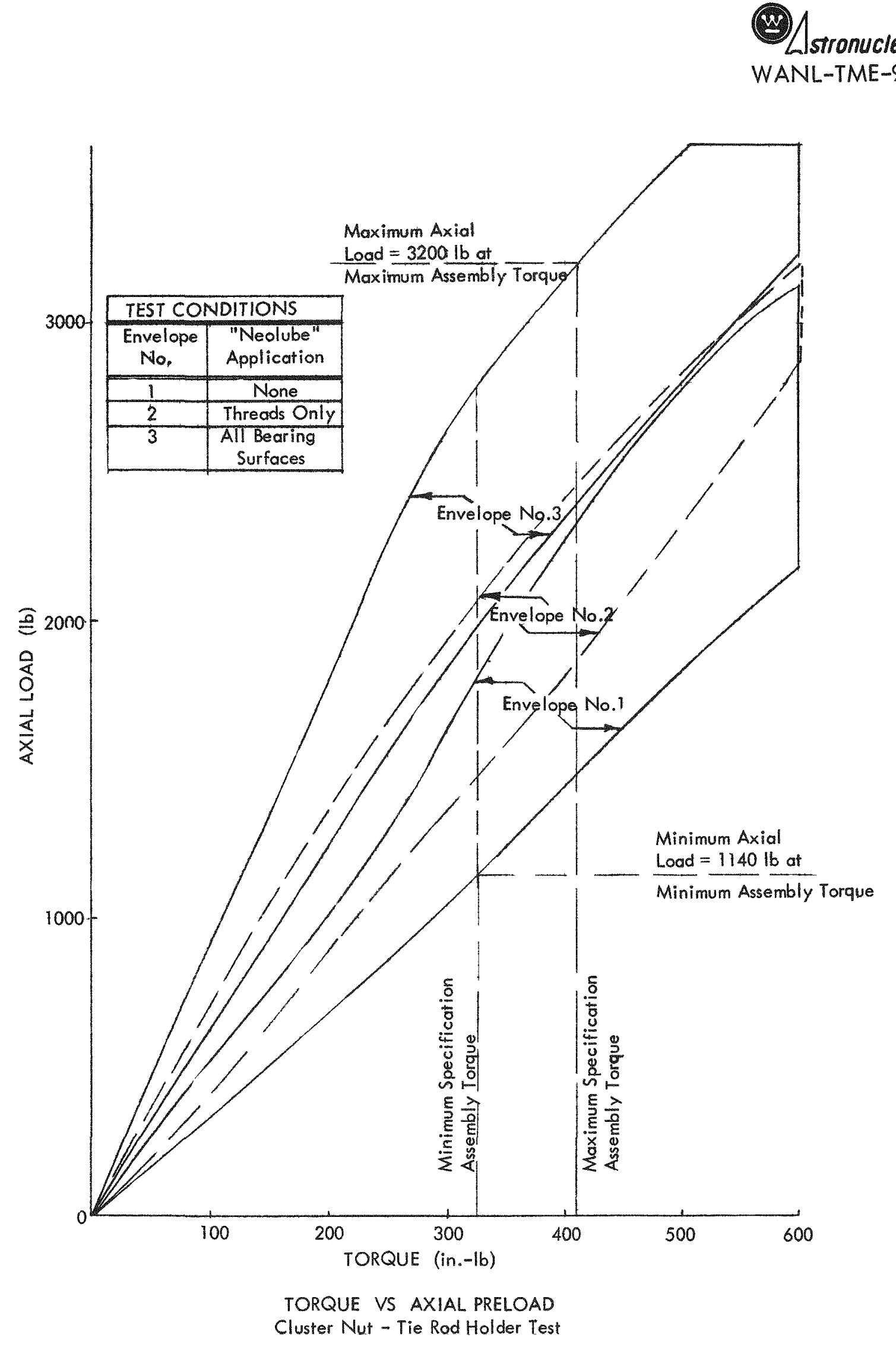

FIGURE I 


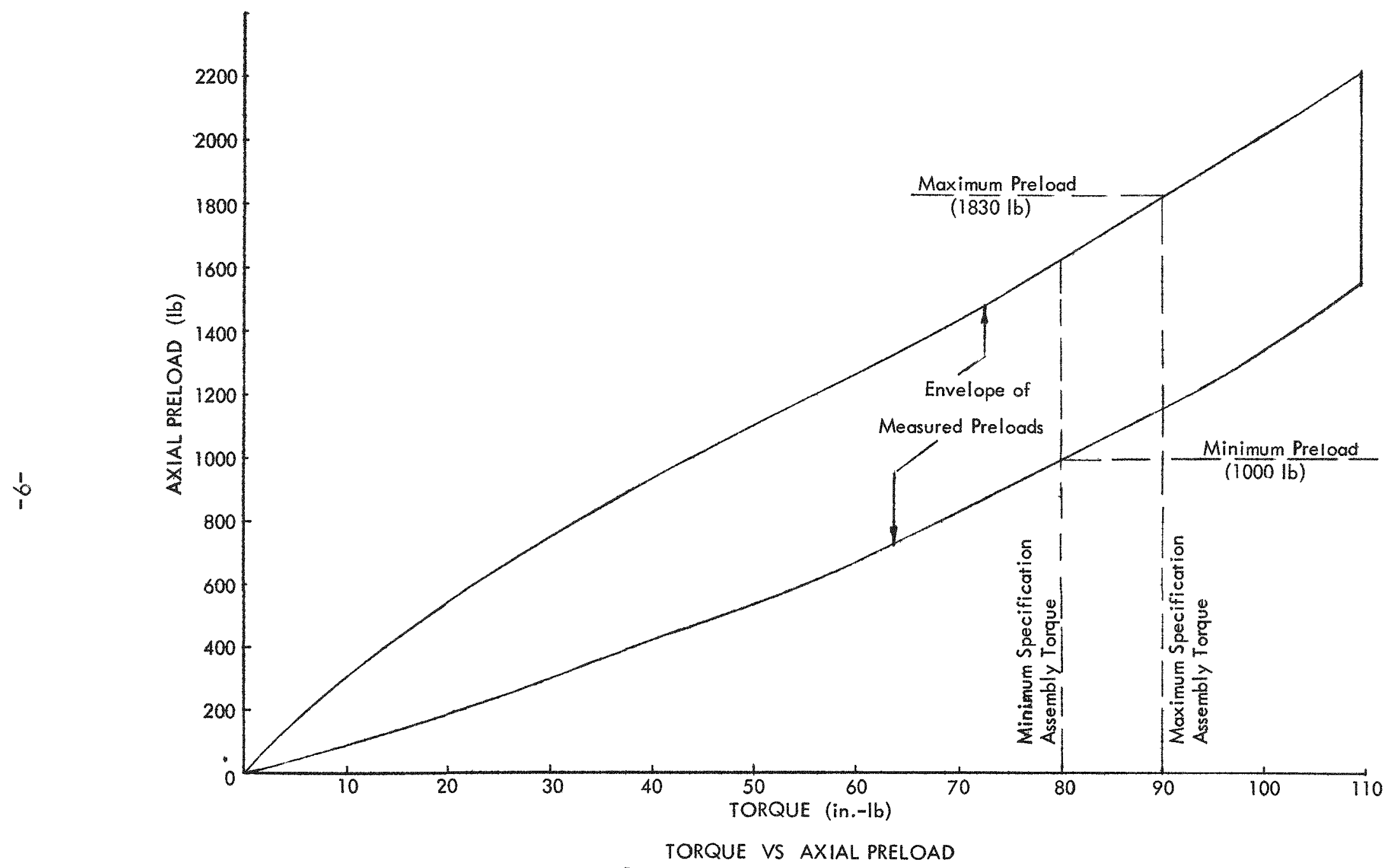

Core Support Plate - Core Support Ring Attachment Bolts

FIGURE 2

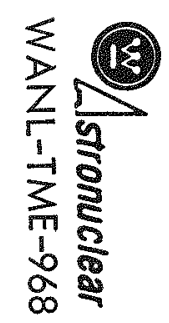



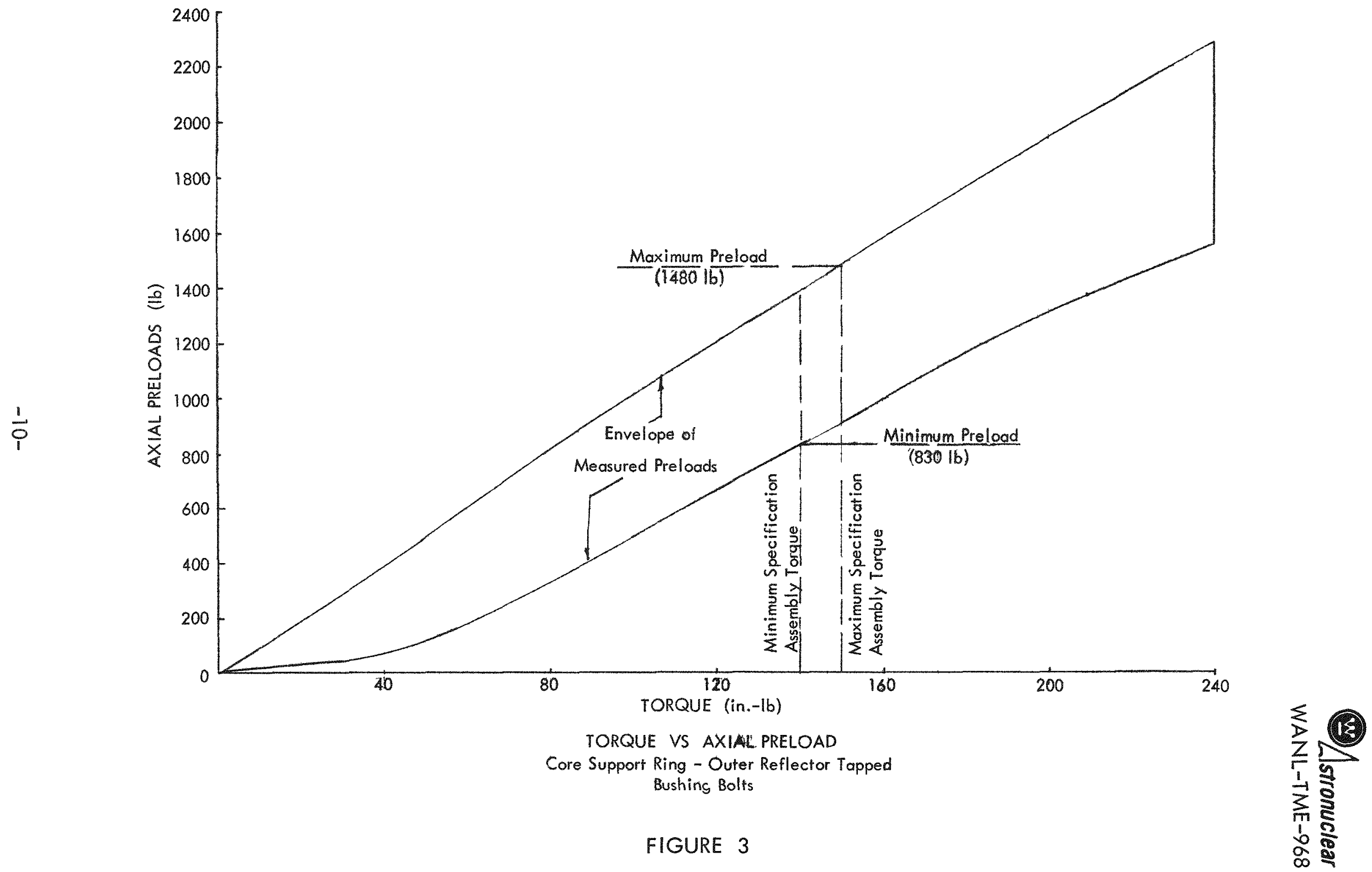


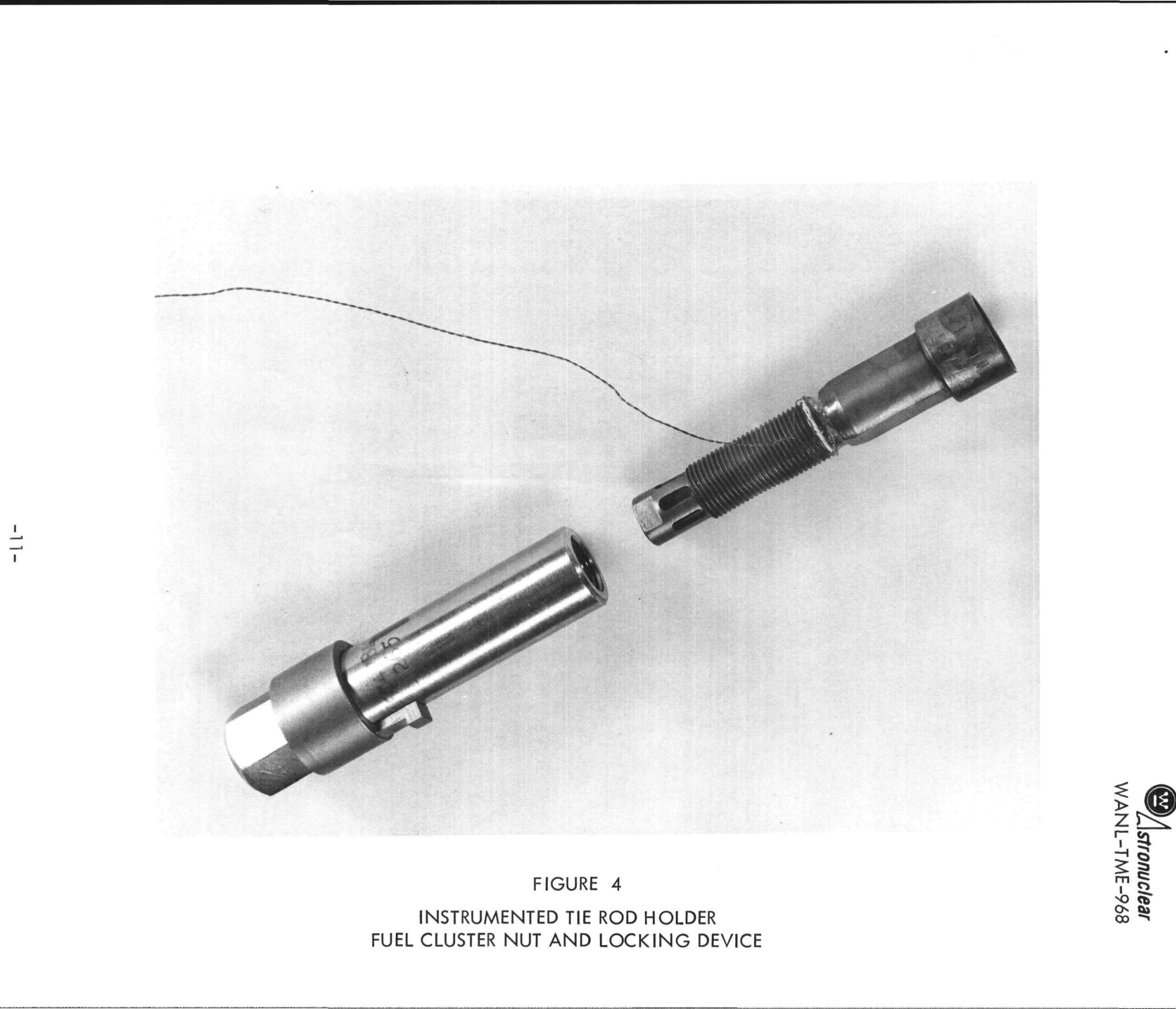




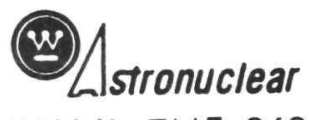

WANL-TME-968

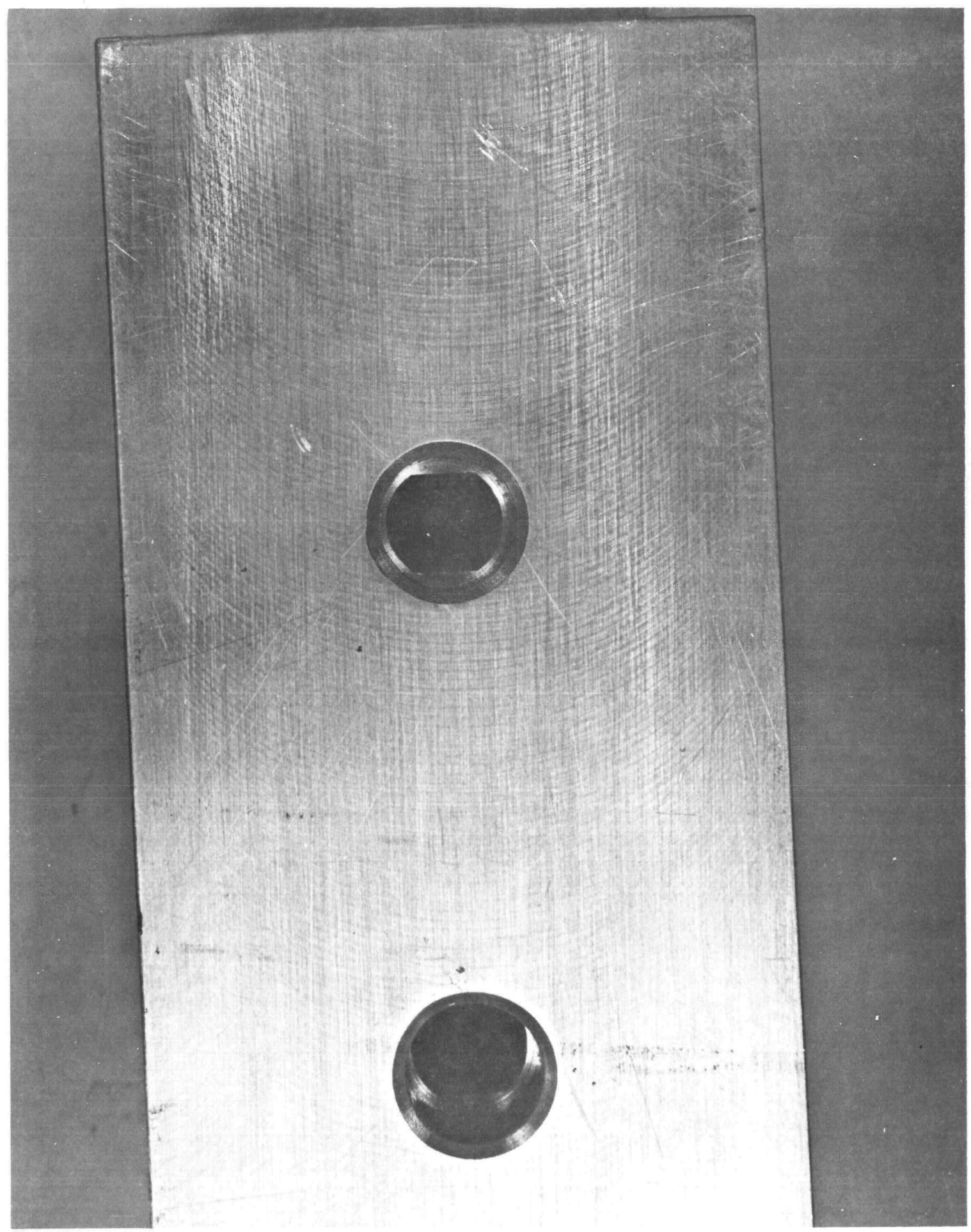

\section{FIGURE 5}

TIE ROD HOLDER HOLES IN SIMULATED CORE SUPPORT PLATE BLOCK 


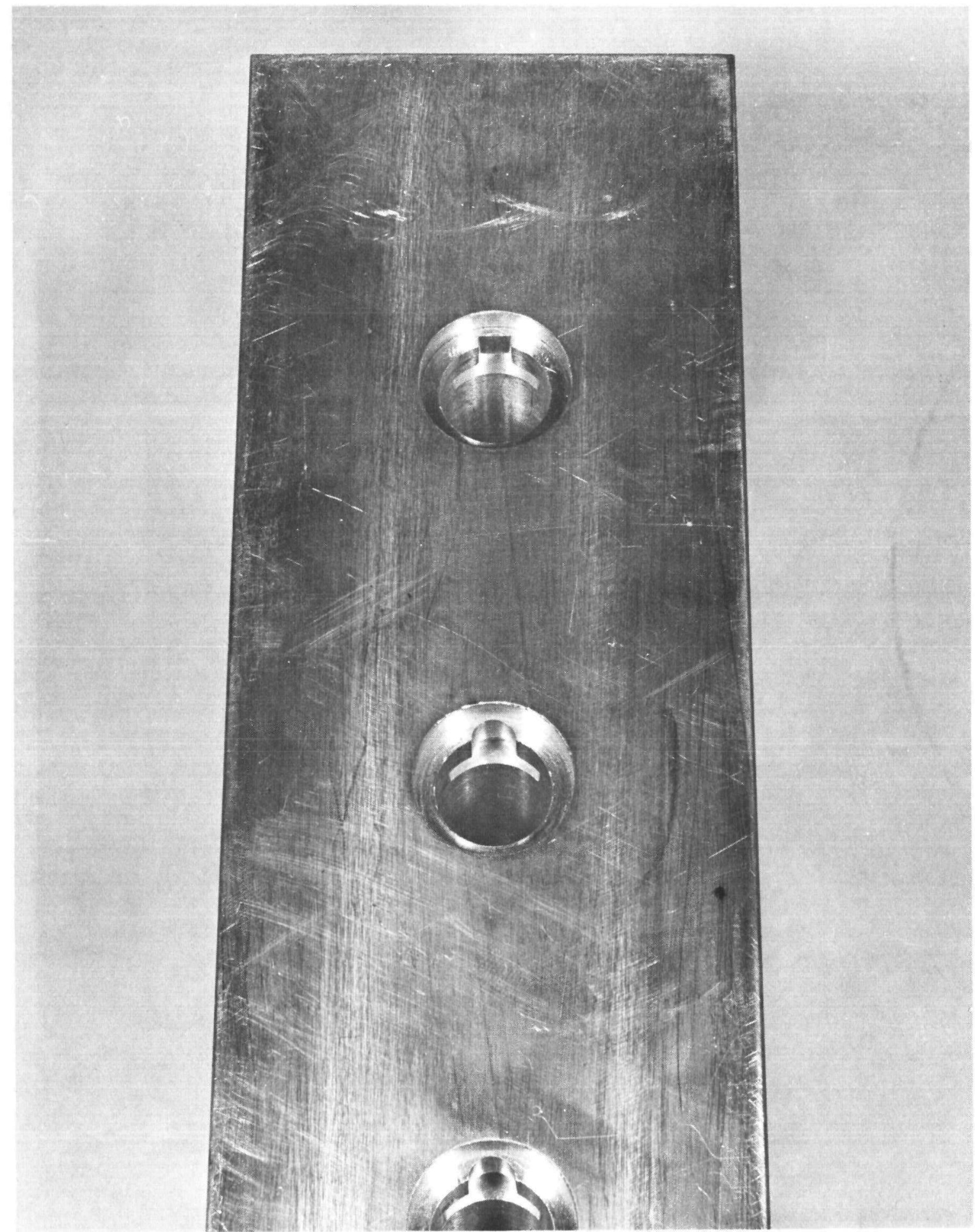

FIGURE 6

LOCKING DEVICE SLOTS IN SIMULATED CORE SUPPORT PLATE BLOCK 


\section{(v) Stronuclear \\ WANL-TME-968}

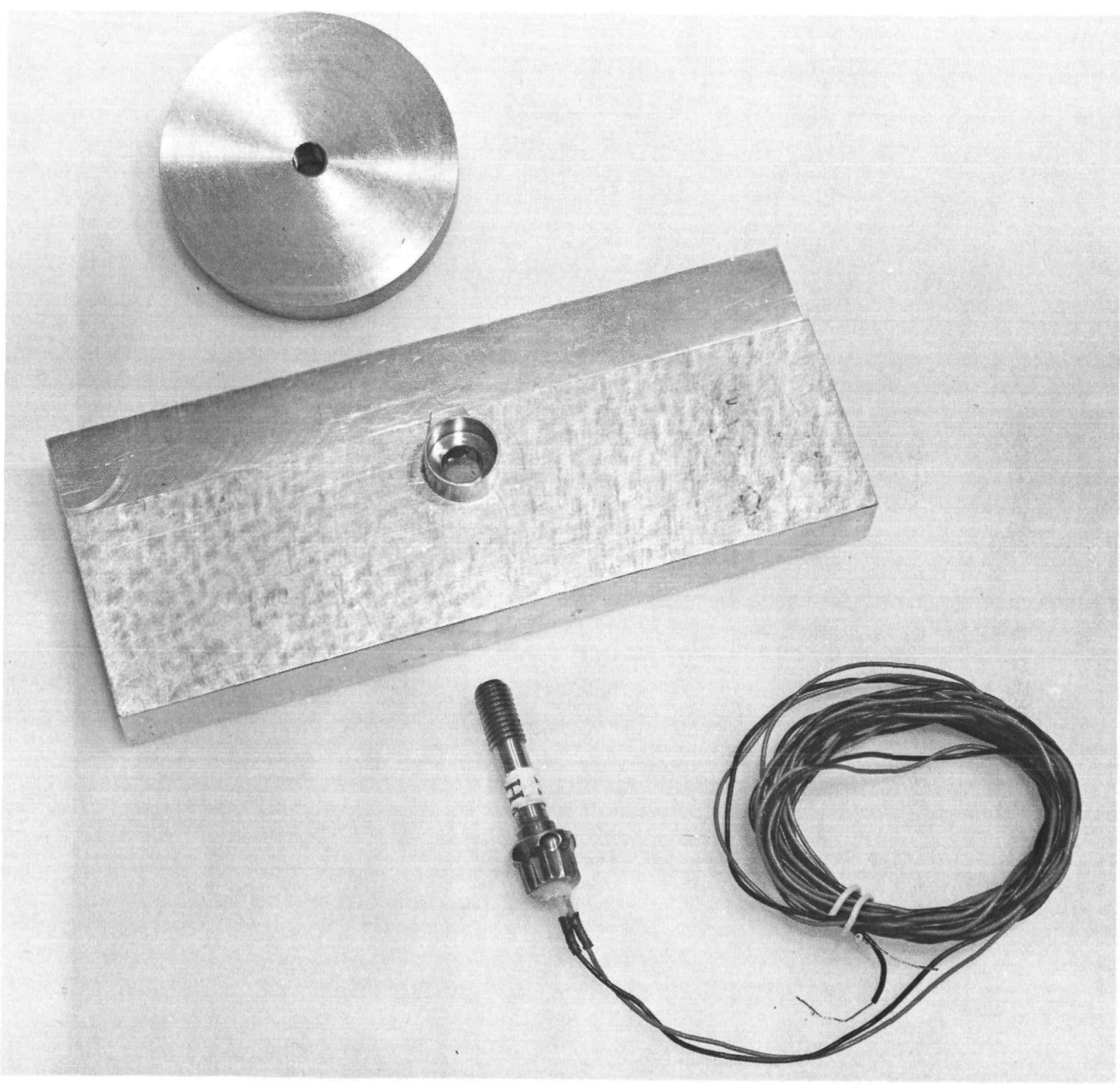

FIGURE 7

INSTRUMENTED 1/4-28 BOLT AND TEST FIXTURE 


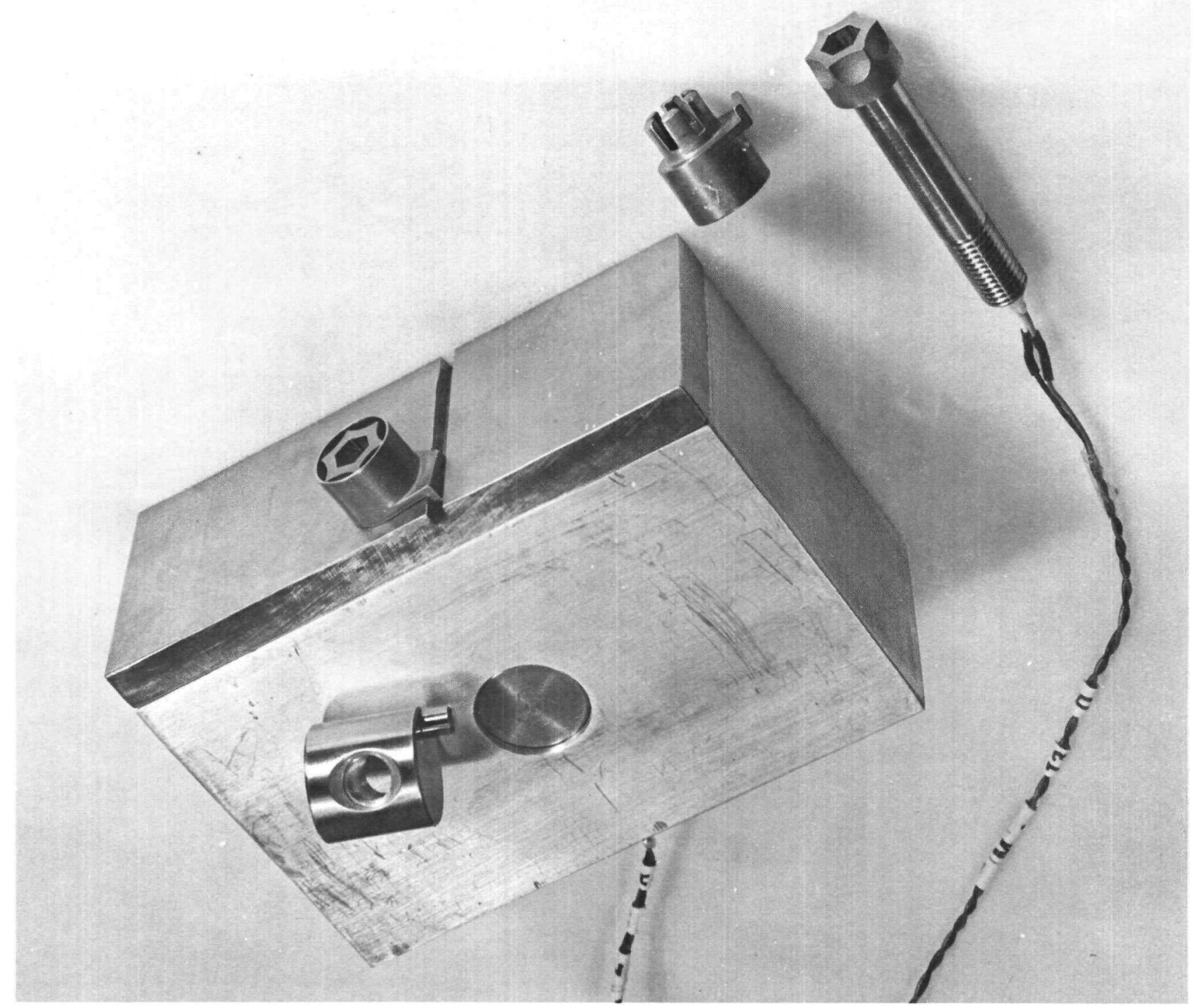

FIGURE 8

INSTRUMENTED 5/16-24 BOLTS, LOCKING DEVICE, NI-SPAN-C BARREL NUT AND TEST FIXTURE 

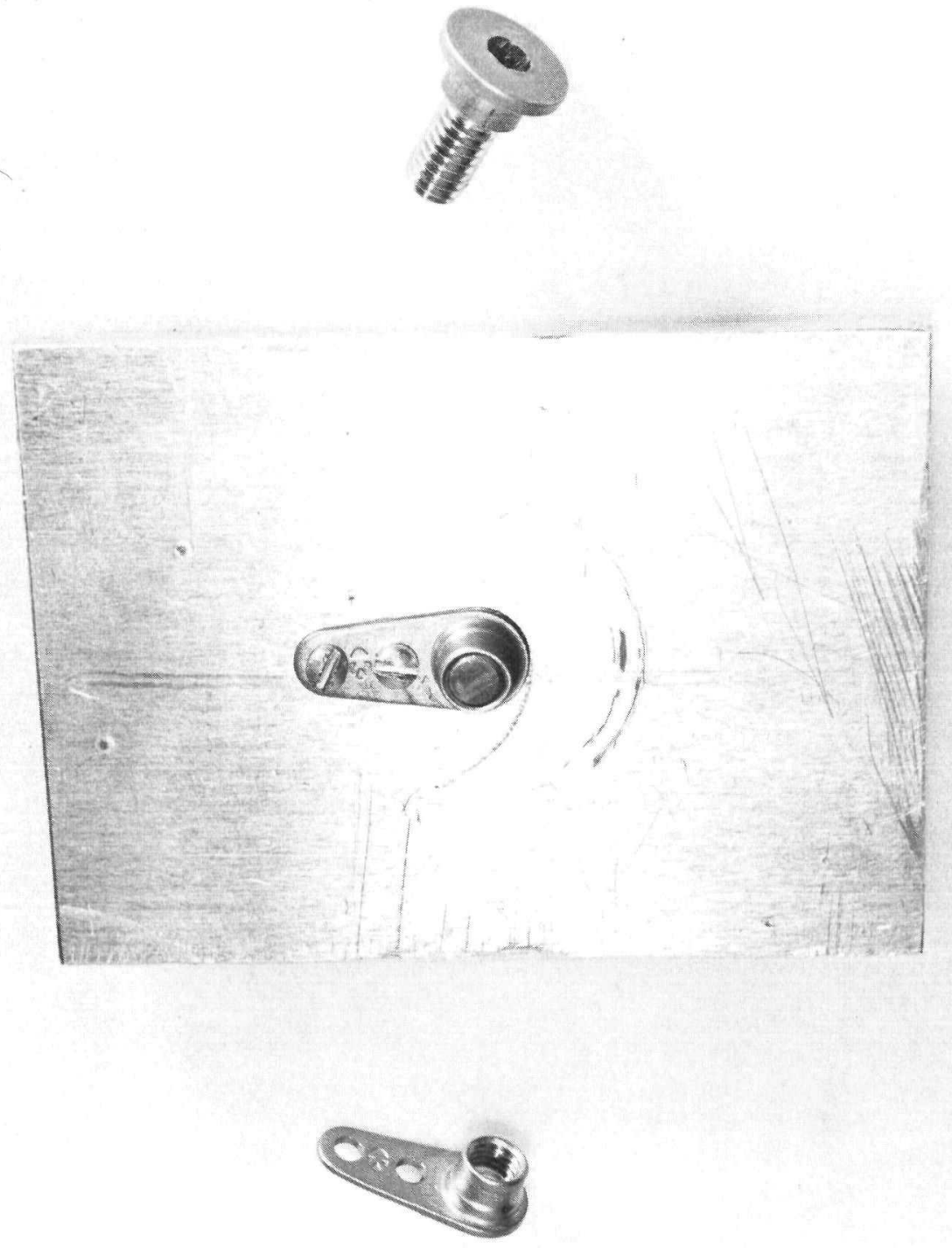

FIGURE 9

BARREL SCREW AND ANCHOR NUT PLATE ASSEMBLY 


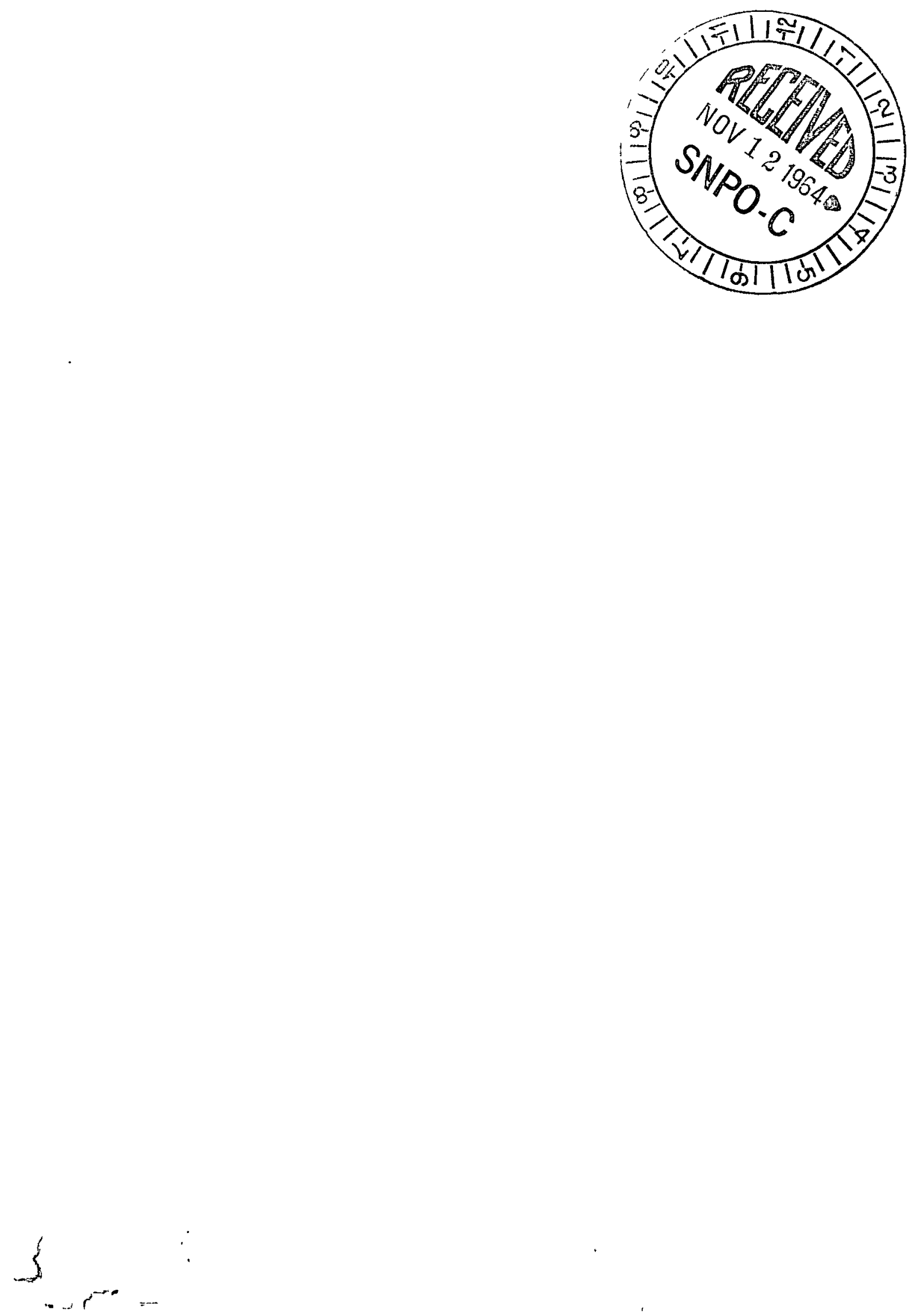